American J. of Engineering and Applied Sciences 4 (1): 108-115, 2011

ISSN 1941-7020

(C) 2010 Science Publications

\title{
Shear Strength of Reinforced Concrete Beam Strengthened by Transverse External Post-tension
}

\author{
${ }^{1}$ Sayan Sirimontree, ${ }^{2}$ Boonsap Witchayangkoon, \\ ${ }^{3}$ Nathavudh Khaosri and ${ }^{1}$ Jaruek Teerawong \\ ${ }^{1}$ Department of Civil Engineering, \\ Khonkaen University, Khonkaen 40002, Thailand \\ ${ }^{2}$ Department of Civil Engineering, Thammasat University, \\ Rangsit Campus, Pathumthanee 40002, Thailand \\ ${ }^{3}$ Department of Engineering, Structural Engineer, Inter-Consult Co., Ltd. Thailand
}

\begin{abstract}
Problem statement: Shear failure of concrete beam is brittle manner without warning so inadequate design for shear of beam and/or material deterioration lead to the possibility of sudden failure of beam. The change of functional use and future increased load of structure lead to the need for strengthening of concrete structure. Approach: This research focuses on behaviors under static loading of reinforced concrete beam, with shear strengthening by transverse external prestressing force. Post-tension high strength steel is vertically applied in shear span. Total eight beam specimens are divided into two groups each having shear span to depth ratios 2 and 1.5. Each beam, possessing the same reinforcing steels, is intentionally designed to be failing in shear. One of the beams from each group is used as reference, without shear strengthening. The other three specimens from each group are applied different amounts of external prestressing force. Results: The experimental result shows that ultimate load carrying capacity of all shear strengthened specimens significantly improves over the reference specimen. The higher the amount of applied strengthening force, the greater the ability to carry ultimate loading. Failure mode shifts from brittle shear failure closer to ductile flexural failure, with higher ductility and stiffness. External prestressing force in transverse direction of shear span of beam enhances ultimate shear capacity by improving aggregate interlocking, preventing splitting cracks caused by debonding of longitudinal reinforcing steels due to dowel action. Furthermore, load at first diagonal tension cracks are increased as a result of pre-compressed prestressing force leading to the higher ultimate load carrying capacity. Moreover, concrete in compression zone remains uncrushed at ultimate state. Strut-and-tie model can be used to predict ultimate loading capacity of beam specimen and failure mechanism of both specimens with or without strengthening. Conclusion: Shear strength of reinforced concrete beams strengthened by transverse external post tension at shear span is effectively improved over reference beam specimen. Strut and tie model can be conservatively predicted the ultimate shear capacity of both reference and strengthened beam specimen.
\end{abstract}

Key words: External post-tension, external prestressing, shear strengthening, Strut-Tie Model (STM), diagonal tension, Reinforced Concrete (RC), diagonal cracks, vertical static

\section{INTRODUCTION}

Many aged concrete structures become deteriorated, damaged or needed to improve their serviceability and strength in order to bear higher loads. Strengthening these structures is thus a must (Yalciner and Hedayat, 2010). Most researches have been focused on flexural strengthening of Reinforced Concrete (RC) beams, while the research on shear strengthening of RC beams is very limited. In fact, it is very dangerous for structures to be brittle failure by shear force. This is due mainly to the structural failure mechanism by shear instantly occurred without warning. Beams mainly subjected to shear force are deep beam, with shear span to effective depth ratio (a/d) less than two (Park and Paulay, 1975). Behaviors of deep beam subjected to vertical static loading are significantly different from behaviors of slender beam, in both analytical method and design.

From previous researches, most of the shear strengthening method involved the use of carbon fiber sheets or steel plates glued to the beam with various 
types of epoxies (Khaloo, 2000, Khalifa et al., 2000, Tenng et al., 1996 and Lorenzis and Nanni, 2001, Alam and Jumaat, 2009; Nilson; 2003). According to the type of failure that frequently occurred, bonding between strengthening material and concrete surface is loose and split up before the failure of either strengthening material or the concrete itself. As a result, ultimate load carrying capacity of beam cannot be precisely predicted.

Bolting or anchoring one end of carbon fiber sheets or steel plates into the beam surface will disturb the concrete beam, producing smaller cross-sectional area of the beam. Even cracks can possibly be found. As a result, concrete beam with shear strengthening by these methods cannot bear high shear as strength of the material allowed.

This research puts spotlight on the behaviors under static loading of reinforced concrete beam with shear strengthening by transverse external prestressing (posttension) force. In this study, PC strand, $12.7 \mathrm{~mm}$ diameter, is used in vertical direction over the shear span. The investigations include the following characteristics: ultimate load capacity, stiffness, ductility and failure mode of the beam specimens. Having the experimental results, it is also possible to choose to appropriated simple analytical model to predict ultimate loading capacity of deep beam with or without shear strengthening by means of external prestressing.

\section{MATERIALS AND METHODS}

Experimental research description and methodology: According to shear span to depth ratio, eight beam specimens are divided into two groups. Each having four beam specimens, groups B1 and B2 possess shear span to depth ratio 1.5 and 2, respectively. One beam specimen from each group (B1$\mathrm{C}$ and $\mathrm{B} 2-\mathrm{C}$ ) is used as reference, for comparison purpose. The other three beam specimens from each group incorporate shear strengthening from different levels of post-compression stresses.

Design of the beam specimens: This experiment, the strut-and-tie model (American Concrete Institute, 2008) is used for RC deep beam specimens design. This simplified design method is appropriate for predicting ultimate loading capacity of RC deep beam and other disturbed region such as corbel and anchorage zone of posttensioned beam (American Concrete Institute, 2008). Arrangement of RC steels for all beam specimens is the same, as indicated in Fig. 1. All beam specimens are designed and expected to fail in shear so steel area and spacing of stirrup less than minimum requirement of deep beam is provided. This will help to clearly demonstrate increased structural performance such as strength, stiffness and ductility after incorporate shear strengthening.
$25,25,25,25,25,25,25,25,25,25,25,25$,

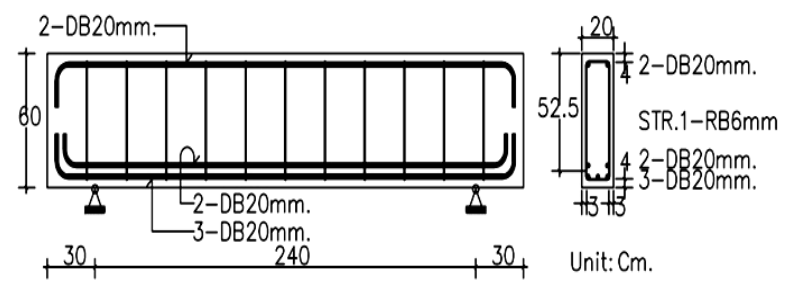

Fig. 1: Detail of RC steels for all beam specimens

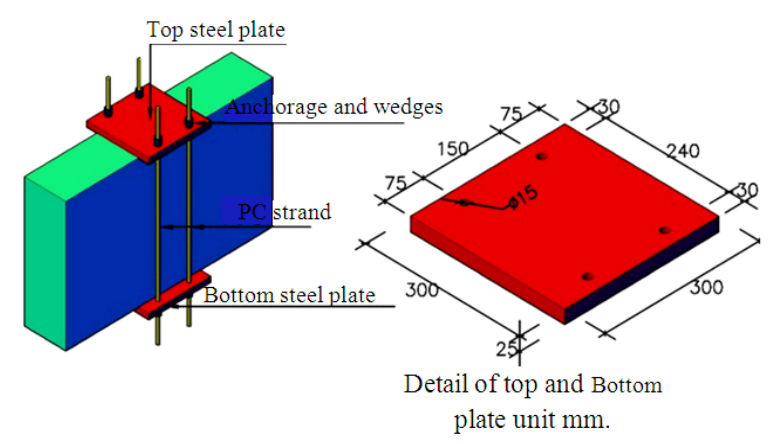

Fig. 2: Shear strengthening apparatus

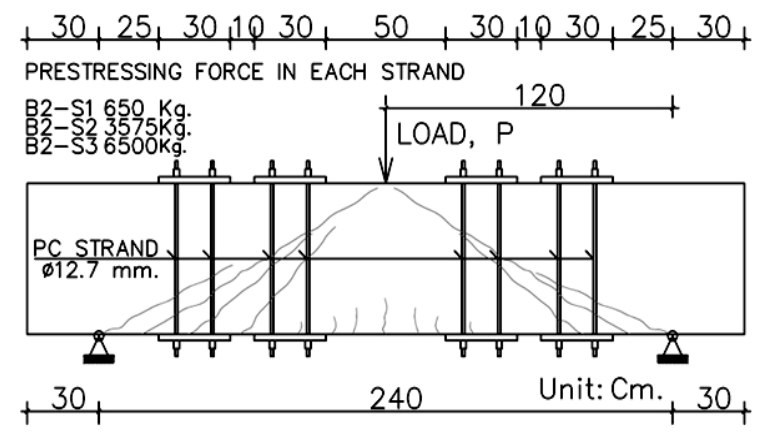

Fig. 3: Cracks occurred in the reference beam specimen and positions of shear strengthening for beam specimens group B2

Design of the strengthened beam: For each beam specimen, there are three levels of bearing stress under steel plate produced by transverse external prestressing force in transverse direction of the beams, as shown in Table 1. The maximum bearing stress is limit to allowable bearing stress for concrete, $25 \%$ of compressive strength of concrete $\left(0.25 f_{c}{ }^{\prime}\right)$. The minimum bearing stress is used to pre-loading of external PC strand. Diagonal tension crack and failure pattern of reference specimen give information for strengthening in shear span as shown in Fig. 3 and 4. Detail of shear strengthening apparatus is illustrated in Fig. 2. 
Am. J. Engg. \& Applied Sci., 4 (1): 108-115, 2011

Table 1: Bearing stress $\left(f_{\mathrm{ci}}\right)$ under steel plate utilized in strengthening

\begin{tabular}{llll}
\multicolumn{3}{c}{ for each beam } & \\
\hline Beam & $\begin{array}{l}\text { Bearing } \\
\text { Stress }\end{array}$ & $\begin{array}{l}\text { Tension Force } \\
\text { in PC Strand }\end{array}$ & $\mathrm{f}_{\mathrm{c}} / \mathrm{f}_{\mathrm{c}}{ }^{\prime}$ \\
\hline & $(\times 0.1 \mathrm{Mpa})$ & $(\times 10 \mathrm{~N})$ & Ratio \\
B2-S1 & 2.50 & 1,500 & 0.014 \\
B2-S2 & 24.00 & 14,400 & 0.132 \\
B2-S3 & 43.50 & 26,100 & 0.240 \\
B1-S1 & 2.50 & 1,500 & 0.014 \\
B1-S2 & 24.00 & 14,400 & 0.132 \\
B1-S3 & 43.50 & 26,100 & 0.240 \\
\hline
\end{tabular}

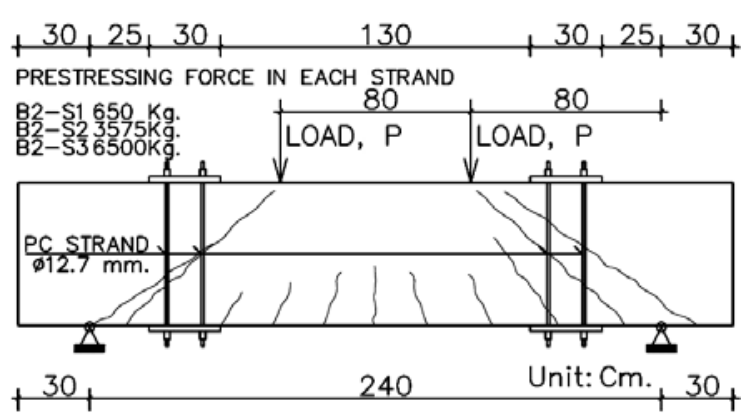

Fig. 4: Cracks occurred in the reference beam specimen and positions of shear strengthening for beam specimens group B1

Testing the beam specimens: All beam specimens are statically loaded by hydraulic jack and load cell placed under loading part of hydraulic jack is used as sensors to quantify load value. Mid span deflection is measured by displacement transducer. Strain measurements are made at the main longitudinal reinforcing steels, stirrup steels, top surface of concrete beam, along compression strut and perpendicular to compression strut. All data at every step of loading (1 ton force) are simultaneously recorded using data-logger. Crack pattern and propagation are recorded by digital camera while crack width is measured by crack comparator.

\section{RESULTS}

Experimental results: Structural behaviors of test specimens are considered by relationship of loadmidspan deflection, ultimate loading capacity, ductility, stiffness and failure mode. Due to brittle shear failure in reference beam specimens before yielding of longitudinal tension steels, ductility of beam specimen, in this study, is considered from deformation ratio, the ratio of ultimate mid-span deflection of strengthened beam to ultimate mid-span deflection of reference beam. Beam stiffness is obtained from slope of a graph between load and mid-span beam deflection. Stiffness of strengthened beam, slope of load-deflection curve, is taken at deflection which is equal to ultimate deflection of reference beam specimens.

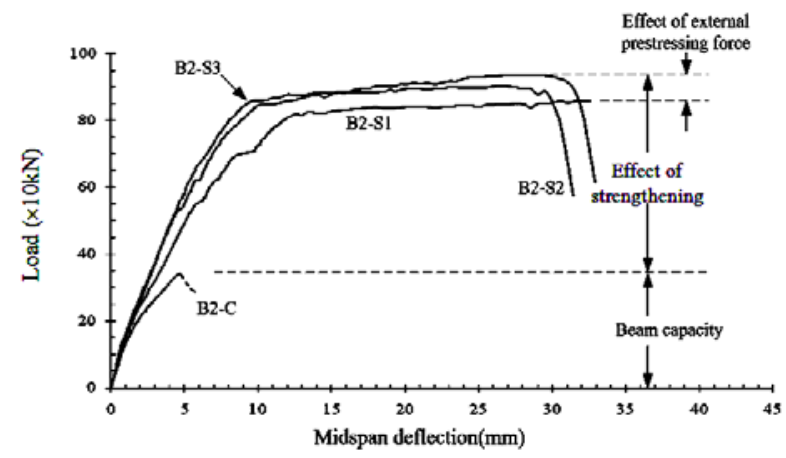

Fig. 5: Relationship between load and mid-span deflection for group B2 specimens

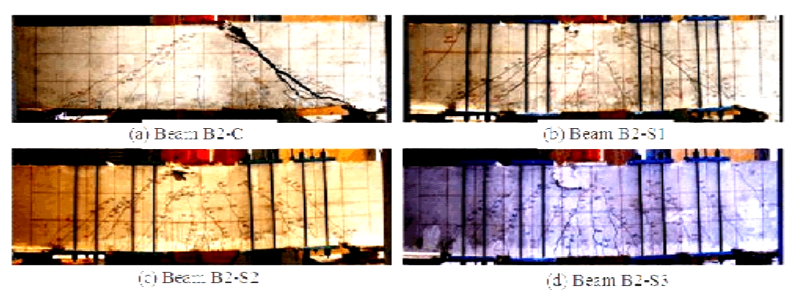

Fig. 6: Failure patterns of group B2 beam specimens

Group B2 beam specimens: Beam specimens group B2, shear span to depth ratio 2.0, with shear strengthening are labeled B2-S1, B2-S2 and B2-S3. It is found from Fig. 5 that ultimate loading capacity of these specimens is significantly higher than that of the reference specimen (B2-C). Specimens with higher to lower tension force in PC strand can bear ultimate loadings 937 (B2-S3), 903 (B2-S2) and 858 (B2-S1) kN, respectively. When comparing to the reference specimen, these shear strengthening specimens hold ultimate loadings corresponding to 175.6, 165.6 and 152.4\%.

In another word, the highest ultimate loading corresponds to the specimen with the highest tension force in PC strand and vice versa. From the experimental results, one can notice that the highest and the lowest ultimate loadings are not significantly different.

In addition, it is found that the beam stiffness depends on level of external prestressing force. Furthermore, this shear strengthening method causes beam ductility to increase. The highest ductility takes place when prestressing reaches $0.25 \mathrm{Mpa}\left(0.014 \mathrm{f}_{\mathrm{c}}{ }_{\mathrm{c}}\right)$. The lowest ductility occurs when prestressing reaches $2.4 \mathrm{Mpa}\left(0.132 \mathrm{f}_{\mathrm{c}}{ }^{\prime}\right)$.

Failure mechanism of specimens B2 begins with vertical cracks in the mid-span region at the bottom portion of the beams where flexural cracking occurs. 
Table 2: Experimental results from testing beam specimens

\begin{tabular}{|c|c|c|c|c|c|}
\hline Beam & $\begin{array}{l}\text { Ultimate } \\
\text { load, } \\
\mathrm{P}_{\mathrm{n}}(\mathrm{kN})\end{array}$ & $\begin{array}{l}\text { Deflection } \\
\text { (mm.) }\end{array}$ & $\begin{array}{l}\text { Deformation } \\
\text { Ratio }^{1} \\
(-)\end{array}$ & $\begin{array}{l}\text { Stiffness }{ }^{2} \\
(\mathrm{kN} / \\
\mathrm{mm} .)\end{array}$ & $\begin{array}{l}\text { Failure } \\
\text { mode }\end{array}$ \\
\hline$\overline{\mathrm{B} 2-\mathrm{C}}$ & 340 & 4.74 & 1.00 & 71.7 & $\begin{array}{l}\text { SDC } \\
\end{array}$ \\
\hline B2-S1 & 858 & 30.53 & 6.44 & 99.2 & SDC \\
\hline B2-S2 & 903 & 24.53 & 5.18 & 112.2 & SC \\
\hline B2-S3 & 937 & 28.04 & 5.92 & 118.2 & $\mathrm{FF}$ \\
\hline B1-C & 843 & 8.01 & 1.00 & 105.2 & SDC \\
\hline B1-S1 & 1228 & 15.52 & 1.94 & 122.3 & SC \\
\hline B1-S2 & 1346 & 14.00 & 1.75 & 137.3 & FCS \\
\hline B1-S3 & 1337 & 14.52 & 1.81 & 137.3 & FCS \\
\hline
\end{tabular}

Table 3: Ratio of flexural and diagonal cracking load per its ultimate loading capacity

\begin{tabular}{lllll}
\hline & Cracking load $(\times 10 \mathrm{kN})$ & \multicolumn{2}{l}{ Load ratio } & \\
& - & - & - & \\
Beam & Flexural, $\mathrm{P}_{\mathrm{f}}$ & Diagonal, $\mathrm{P}_{\mathrm{d}}$ & $\mathrm{P}_{\mathrm{f}} / \mathrm{P}_{\mathrm{u}}$ & $\mathrm{P}_{\mathrm{d}} / \mathrm{P}_{\mathrm{u}}$ \\
\hline B2-C & 20.00 & 20.00 & 0.59 & 0.73 \\
B2-S1 & 17.00 & 24.00 & 0.20 & 0.35 \\
B2-S2 & 16.00 & 32.00 & 0.18 & 0.59 \\
B2-S3 & 16.00 & 68.00 & 0.17 & 0.73 \\
B1-C & 24.00 & 36.00 & 0.28 & 0.47 \\
B1-S1 & 24.00 & 44.00 & 0.20 & 0.35 \\
B1-S2 & 28.00 & 64.00 & 0.21 & 0.47 \\
B1-S3 & 28.00 & 74.00 & 0.21 & 0.55 \\
\hline
\end{tabular}

Three shear strengthening specimens reveal flexural cracking at loading about $20 \%$ of ultimate loading capacity. For the reference specimen, after flexural cracking occurred, diagonal tension cracking is occurred and propagated between regions running from loading point to the two supports (Fig. 6). Thereafter, diagonal cracks become progressively more widen until the reference specimen reaches ultimate limit state. For the three shear strengthening specimens, less diagonal cracks are seen as increasing external prestressing force.

Considering specimen B2-S1, even though external prestressing is applied, but it does not intensify enough to control diagonal cracks. This leads to brittle failure of the specimen as a result of initiated diagonal cracks at low applied load level. For specimen B2-S2, higher external prestressing force provides ability to better control diagonal cracks width. This lead to more ductile failure of specimen as demonstrated from the experiment, it is evident that the B2-S2 fails due to shear compression failure.

For specimen B2-S3, diagonal cracks occurred between the loading points and its two supports (shear span) are in control as a direct result of full external prestressing. The specimen does not fail by shear. Instead, the specimen turns to have clear flexural behavior and fails in flexural mode.

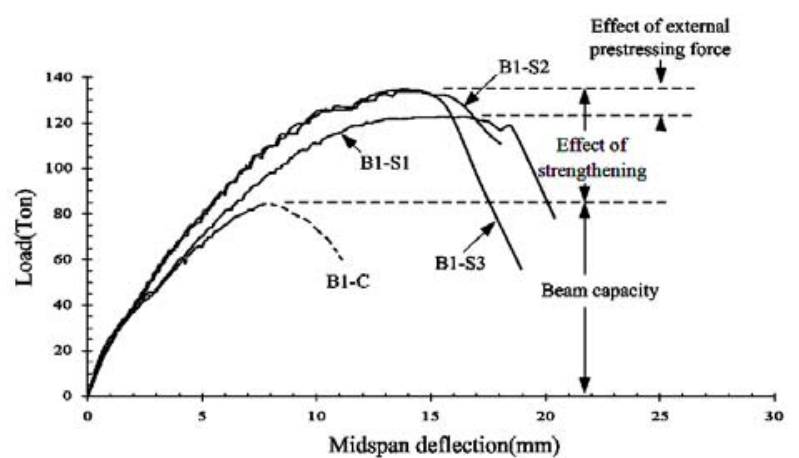

Fig. 7: Relationship between load and mid-span deflection of group B1 beam specimens

According to Table 2 and 3, beam specimens having greater external prestressing exhibit capability to bear higher load induced first diagonal cracks. Based on strain data of stirrup and PC strand from experiment, it was found that with the minimum external prestressing force $\left(0.014 \mathrm{f}_{\mathrm{c}}{ }^{\prime}\right)$, stirrup steels start to work before increased tensile strain occurs in PC strands. With higher external prestressing force $\left(0.132 \mathrm{f}_{\mathrm{c}}\right)$, stirrup steels work together with increased tensile strain occurs PC strands. With the maximum external prestressing force $\left(0.24 \mathrm{f}_{\mathrm{c}}{ }^{\prime}\right)$, PC strands start to work before tensile strain occurs in stirrup steels.

Group B1 beam specimens: As higher external prestressing force has direct effect on greater shear strength, the ultimate loading capacities are thus higher according to degrees of external prestressing. The group B1 beam specimens with shear strengthening are labeled B1-S3, B1-S2 and B1-S1 having ultimate loading capacities 1377, 1346 and 1228 respectively. When comparing to the reference specimen, these ultimate loadings corresponding to 158.6, 159.7 and $145.7 \%$, respectively.

In Fig. 7 and 8 the graph plotted between load and mid-span deflection shows that specimen B1-S1 has lowest slope where as specimens B1-S2 and B1-S3 exhibit similar slopes. For working load within elastic portions, specimens B1-S2 and B1-S3 illustrate smaller deflection compared to specimen B1-S1 for the same loading. Moreover, all shear strengthening specimens demonstrate significant higher ductility compared to the reference specimen.

First crack occurs at load about $20 \%$ of the ultimate loading capacity due to flexure for all specimens in Group B1. This load is first caused by flexural cracking moment. Diagonal tension crack initiates and propagates at higher load level after flexural cracking. 

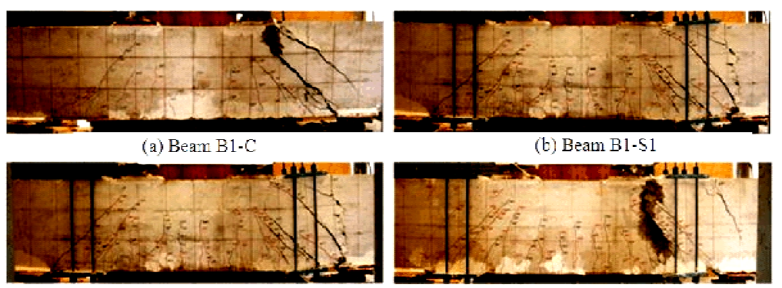

(c) Beam B.1-\$1

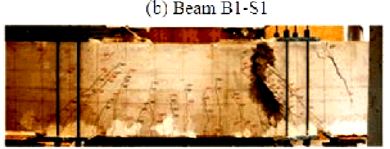

(d) Beam B1-S1

Fig. 8: Failure pattern of B1 Group

All B1 specimens fail as a result of diagonal cracking between loading point and the two supports (shear span). Prestressing forces control diagonal cracks and their propagation. Because the specimens in this series are considered as deep beam so transverse applied load is transfer to support by shear, diagonal cracks due to principle tensile stress produced by shear still occur when this stress reach tensile strength of concrete. However, external prestressing is proved its ability to control the first diagonal cracks, producing the specimens to have higher shear or loading capacity.

\section{DISCUSSION}

Analysis and discussion of the experimental results: Beam specimens from both two groups transfer applied load to beam support by arch action in D-regions (disturbed or discontinuity regions) which is the distance equal to depth from concentrated load for example applied load and support reaction. Load is transferred directly to support via compression strut. The equilibrium system of compression strut force, tension force in longitudinal steel and support reaction is exhibited in Fig. 9.

PC strands used for strengthening increase shear strength portion carried by stirrup $\left(\mathrm{V}_{\mathrm{s}}\right)$. Bearing stress under steel plate as a result of transverse prestressing force enhances shear resistant mechanism by increasing aggregate interlocking $\left(\mathrm{V}_{\mathrm{a}}\right)$. This prevents horizontal splitting in concrete along the longitudinal tension steels as a result of debonding of reinforcing steel and surrounding concrete. This splitting crack is induced by dowel action in shear transfer in D-region.

Transverse prestressing force in strengthened specimen delays diagonal cracking process, thus further shear can be resist by concrete in compression zone $\left(\mathrm{V}_{\mathrm{CZ}}\right)$ which is remain uncrushed, as seen in Fig. 10.

Diagonal tension cracks due to shear force cannot be prevented by stirrup steels but after cracking stirrup will resist tension by developing tensile stress. Another method to resolve shearing effect is to add vertical forces produced by external post tension such that it will directly resist diagonal tension crack due to shear

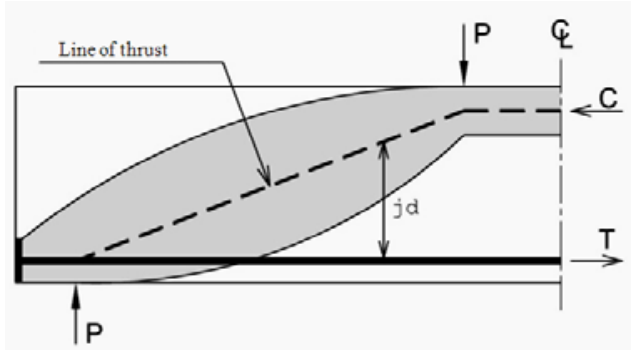

Fig. 9: Arch action formed within the specimen

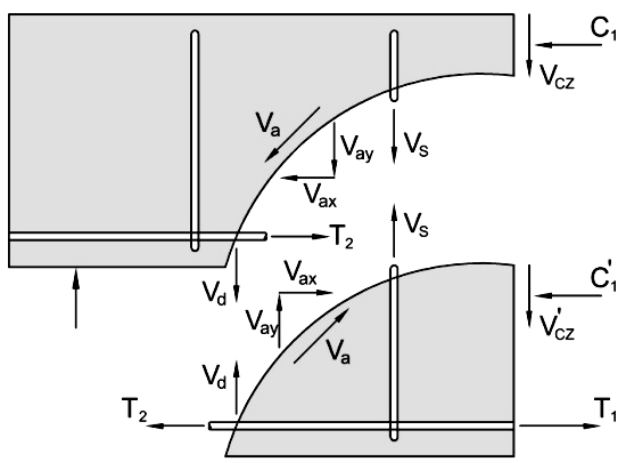

Fig. 10: Shear resistant mechanism of beam with shear reinforcement

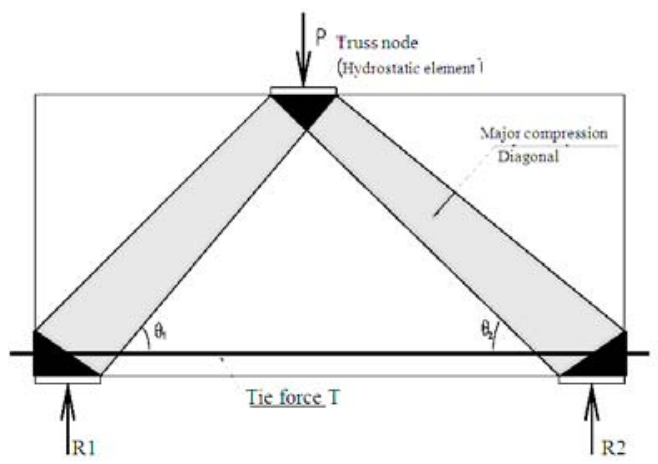

Fig. 11: Strut-and-tie model (American Concrete Institute, 2008)

force. This will increase loading or shear capacity of reinforced concrete beam. When the amount of prestressing force from external post tension is high enough, PC strands will be able to withstand shear by means of developing tension before diagonal tension cracks occurred in concrete. Having cracks under control, failure mechanism of group B2 specimens change from shear to flexural failure. For group B1 specimens, with shorter shear span to depth ratio compared to group B2 specimen, the failure is caused by crushing of compression strut corresponding to highest sectional shear strength of the specimen. 
Table 4: Ultimate loads as from strut-and-tie model, yield loads and ultimate loads as from the experiment

\begin{tabular}{|c|c|c|c|c|c|}
\hline Beam & $\begin{array}{l}\text { Ultimate load } \\
\text { from STM, } \\
\mathrm{P}_{\text {STM }}(\times 10 \mathrm{kN})\end{array}$ & $\begin{array}{l}\text { Yield } \\
\text { load, } \mathrm{P}_{\mathrm{y}} \\
(\times 10 \mathrm{kN})\end{array}$ & $\begin{array}{l}\text { Ultimate } \\
\text { load, } P_{n} \\
(\times 10 \mathrm{kN})\end{array}$ & $\begin{array}{l}\mathrm{P}_{\mathrm{y}} / \mathrm{P}_{\text {STM }} \\
\text { Ratio } \\
\end{array}$ & $\begin{array}{l}\mathrm{p}_{\mathrm{u}} / \mathrm{P}_{\mathrm{STM}} \\
\text { Ratio } \\
\end{array}$ \\
\hline$\overline{B 2-C}$ & $32.0^{1}$ & - & 34.0 & - & 1.06 \\
\hline B2-S1 & -* & 82.0 & 85.8 & -* & -* \\
\hline B2-S2 & -* & 88.0 & 90.3 & -* & -* \\
\hline B2-S3 & $65.6^{2}$ & 82.0 & 93.7 & 1.25 & 1.43 \\
\hline B1-C & $50.5^{1}$ & - & 84.3 & - & 1.67 \\
\hline B1-S1 & -* & 120.0 & 122.8 & -* & -* \\
\hline B1-S2 & $-*$ & 120.0 & 134.6 & -* & -* \\
\hline B1-S3 & $98.4^{2}$ & 126.0 & 133.7 & 1.28 & 1.36 \\
\hline
\end{tabular}

-*: Not consider for specimen without maximum compressive force produced by external strand; ${ }^{1}$ : Failure of diagonal compression strut due to effective compressive strength of concrete; ${ }^{2}$ : Failure caused by yielding of main longitudinal reinforcement

The suitable model for prediction of shear strength of deep beam or disturb region (D-region) is strut-tie model proposed by ACI318-05 (American Concrete Institute, 2008). Applied loads transfer to support by principle compressive stress, compression strut and principle tensile stress, tension tie, connect together by node as shown by Fig. 11. Shear strength in term of ultimate load carrying capacity of beam specimen using Strut-and-Tie Model (STM) can be computed according to ACI 318-05 standard as given in Table 4.

The strut-and-tie model used in this study is based on assumptions-before strengthening the strut is in bottle shape having deficit reinforcements and after strengthening strut is in bottle shape having an adequate amount of reinforcements. In addition, horizontal strut form in the top part of specimen has prismatic shape. The node at the loading point is considered as CCC node. Node at each of two supports is considered as CCT node. For node at the upper portion of compression strut caused by strengthening, there is tie enclosed but actual behavior is CCC node. This is due to that PC strands acting as tie do not come across node. Additionally, external force acting on PC strands produces compression at upper node. Lower portion of diagonal strut caused by strengthening is taken as bearing area resisted by main reinforcement. All nodes in the model are considered as extended nodal zone. This causes stress in each nodal section to be different. However, this has no significant impact on the strength of node being considered.

As from various amounts of prestressing force used in this study, the highest prestressing force yields highest ultimate loading capacity. Also, load-deflection behavior improves over the reference specimen. This analysis for ultimate loading capacity using strut-andtie model will therefore not consider the difference amounts of prestressing force, but will focus on the maximum compressed forces and cross sectional area of external PC strand used for shear strengthening.

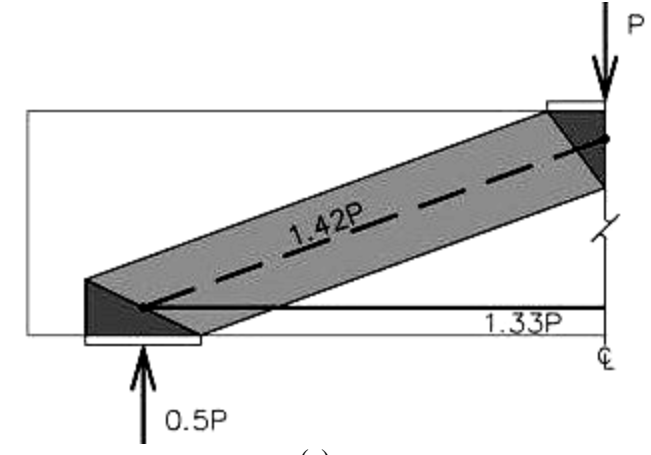

(a)

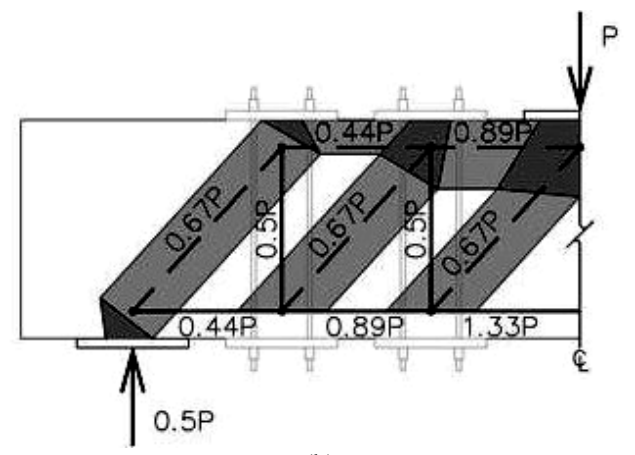

(b)

Fig. 12: Internal load transfer for beam specimens group B2 (a) Control beam group B2 (b) strengthened beam group B2

Strength reduction factor is not included in strength computed by strut-and-tie model (Nominal strength).

From Table 4, it is found that the ultimate loading capacities given from strut-and-tie model are lesser than that obtain from the experiment for specimen B2-C and B1-C. This shows that strut-tie model gives the conservative value of shear strength. In addition, for shear strengthening specimens, loads evaluated by strut-and-tie model are close to yield loads much more than respective ultimate loads obtained from the experiment. This is consistent with the consideration of ultimate load carrying capacity of the test beam by strut-tie model in the case of yielding of the main longitudinal steel. However, ultimate load is still less than yielding load from test results. This might be due to strain hardening effect of longitudinal steel which is not considered in strut-tie model.

Loading mechanism as considering from strut-andtie model is demonstrated in Fig. 12 and 13. Before strengthening, specimen directly transfers load from loading point to support, through compression strut, whereas the main longitudinal steels carry the tension force. These comprise an equilibrium state. In fact, tension force in the main longitudinal steels is constant along its length. 


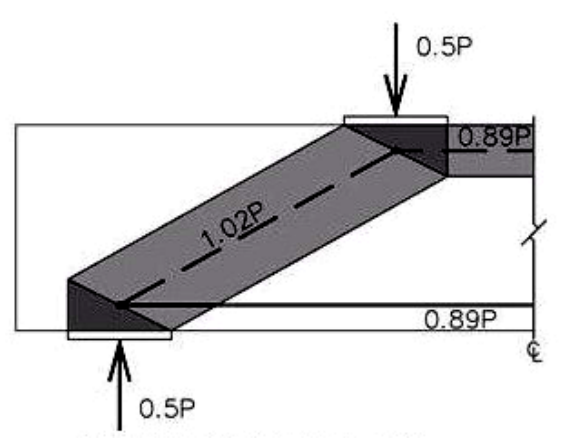

(a)

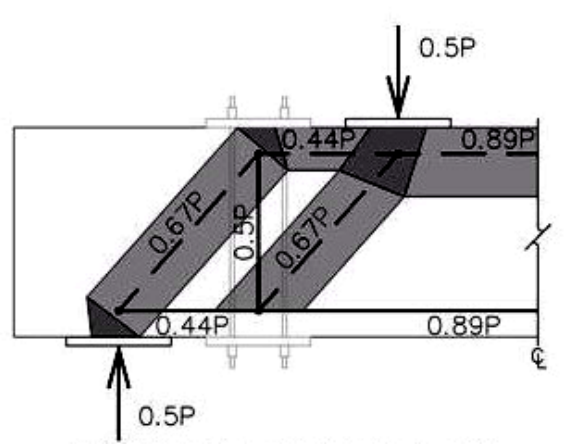

(b)

Fig. 13: Internal load transfer for beam specimens group B1 (a) Control beam group B1 (b) Control beam group $\mathrm{B} 1$

It can be estimated that compression strut carry compression force 1.42 and 1.02 times the loading applied on specimen B2 and B1, respectively. The constant tension force in main longitudinal steels is 1.33 and 0.89 times the loading applied on specimen B2 and B1, respectively.

After having strengthened, PC strands take tension force about $50 \%$ of the loading. In fact, shear is transferred from diagonal cracks through PC strands. Afterward, a new compression strut is formed to transfer applied load, as readily seen from Fig. 12b and $13 \mathrm{~b}$. However, the subsequence compression strut becomes smaller and takes mere $67 \%$ of the applied load as compared to that from the reference specimen. As a result, the specimen can serve higher loads. Furthermore, tension force in the main longitudinal steels is highest at the mid-span portion and shrinks as it comes closer to the support. This is mainly from a new internal strut force along diagonal over shear span helping to resist tension force in the longitudinal main steel. Thus, the specimen nodal zone can escape from failure. Moreover, external prestressing used for strengthening enhances stronger strut. As the specimen is under control to prevent shear failure, it moves closer to ductile failure.

\section{CONCLUSION}

All beam specimens with shear strengthening using vertically installed PC strands post-tension type over shear span are able to take higher ultimate loads compared to the reference specimens. Ductility and stiffness are also improved. As a result, failure mode moves closer to ductile failure. This shear strengthening method needs to do preloading to PC strands. Prestressing force added to PC strands increases diagonal crack resistant behavior as from full loading. Post compression stress under steel bearing plate should be in the range $0.014 \mathrm{f}_{\mathrm{c}}{ }^{\prime}-0.240 \mathrm{f}_{\mathrm{c}}$ ' providing marginal safety. The ultimate load capacities as obtained from the strutand-tie model and experiment with three different amounts of prestressing force, it is found that at highest post compression stress $0.240 \mathrm{f}_{\mathrm{c}}{ }^{\prime}$ yields highest ultimate load capacity and highest stiffness. Ductility of specimens with highest and lowest post compression stresses does not show significant different.

From this study, it can be observed that the strutand-tie model is acceptable to be utilized in finding load capacity with less estimation compared to the experiment. In design process, when using strength reduction factor and load factor, safety index becomes essentially larger.

During failure process of all shear strengthened specimens, PC strands do not lose out indicating that this method provides effective installation especially the effective anchorage at both ends of PC strands. However, this study covers only static loading test. For the case of repeated (reiterative) loading, more behavioral study is needed.

\section{ACKNOWLEDGEMENT}

We are grateful to the Center of Materials Testing, Khonkaen University and Department of Civil Engineering, Thammasat University Rangsit Campus for supporting this research. Also, the authors would like to give special thanks to the Inter-Consult Co., Ltd., Thailand for equipment and financial supports.

\section{REFERENCES}

Alam, M.A. and M.Z. Jumaat, 2009. Eliminating premature end peeling of flexurally strengthened reinforced concrete beams. J. Applied Sci., 9: 1106-1113. DOI: 10.3923/jas.2009.1106.1113

American Concrete Institute, 2008. Building Code Requirements for Structural Concrete and Commentary. ACI Committee 318, Michigan USA. http://www.concrete.org/pubs/newpubs/31808.htm 
Khalifa, A., L. De Lorenzis and A. Nanni, 2000. FRP composites for shear strengthening of RC beams. Proceedings of the 3rd International Conference on Advanced Composite Materials in Bridges and Structures, Aug. 15-18, Ottawa, Canada, pp: 137-144.

Khaloo, A.R., 2000. Shear Repair of Reinforced Concrete Beams Using Post-Tensioning. Special Publication, 193: 519-550.

Lorenzis, L.D. and A. Nanni, 2001. Shear strengthening of reinforced concrete beams with near-surface mounted fiber-reinforced polymer rods. Struct. J., 98: 60-68.

Nilson, A.H., 2003. Design of Concrete Structure. 13th Edn., McGraw Hill India, India, ISBN-10: 0070598541
Park, R. and T. Paulay, 1975. Reinforced Concrete Structure. 1st Edn., John Wiley and Sons Inc., USA., ISBN-10: 0471659177, pp: 800.

Tenng, S., F.K. Kong, S.P. Poh, L.W. Guan and K.H. Tan, 1996. Performance of strengthened concrete deep beams predamaged in shear. Struct. J., 93: 159-170.

Yalciner, H. and A.A. Hedayat, 2010. Repairing and strengthening of an existing reinforced concrete building: A north Cyprus perspective. Am. J. Eng. Applied Sci., 3: 109-116. DOI: 10.3844/ajeassp.2010.109.116 